\title{
Kompozit restorasyonların şekillendirilmesinde kullanılan rezinlerin mikrohibrit kompozitin yüzey özellikleri üzerine etkisi*
}

\author{
Zeynep Bilge Kütük(0000-0003-0562-056X) ${ }^{\alpha}$, Alp Can Dulda(0000-0002-3559-5011) \\ Damla Lara Akşahin(0000-0002-7778-8700) ${ }^{\alpha}$, Zeynep Elif Durak(0000-0003-3879-0856) ${ }^{\alpha}$, Ecem Erden(0000-0003-4443-046X) ${ }^{\alpha}$
}

Selcuk Dent J, 2019; 6: 366-374 (Doi: 10.15311/selcukdentj.629851)

Başvuru Tarihi: 06 Ekim 2019 Yayına Kabul Tarihi: 15 Kasım 2019

\section{öz}

Kompozit restorasyonların şekillendirilmesinde kullanılan rezinlerin mikrohibrit kompozitin yüzey özellikleri üzerine etkisi

Amaç: $\mathrm{Bu}$ in vitro çalışmada kompozit restorasyonların şekillendirilmesinde kullanılan farklı tiplerdeki rezin içerikli modelasyon likitlerinin mikrohibrit bir kompozitin yüzey mikrosertliğine, pürüzlülüğüne ve renk değişimine olan etkisini incelemek amaçlandı.

Gereç ve Yöntemler: Çalışmada kullanılmak üzere $12 \mathrm{~mm}$ çapında ve $2 \mathrm{~mm}$ yüksekliğinde Teflon kalıp ile silindir şeklinde 64 adet mikrohibrit kompozit (Essentia Universal, GC, Tokyo, Japonya) örnek şu şekilde gruplara göre hazırlandı; Grup 1: Kontrol (modelasyon likidi kullanılmadan), Grup 2: Modeling Liquid (GC), Grup 3: G-Premio Bond (GC), Grup 4: OptiBond XTR Primer (KavoKerr). Şekillendirmede kullanılan modelasyon likitleri sadece yerleştirilirken mikrohibrit kompozitin yüzeyine uygulandı ve örneklerin üst yüzeyine şeffaf bant yerleştirildi, sonra $20 \mathrm{sn}$ polimerize edildi. Örneklere 2500-3000 gritlik SiC-kağıtlar ile polisaj yapıldı ve $37^{\circ} \mathrm{C}$ 'deki inkübatörde saklanma ortamına göre (distile su vaya kahve) rastgele 2 gruba ayrıldı $(n=8)$. Yüzey mikrosertliği (VHN), pürüzlülüğü $(\mathrm{Ra})$ ve renk değişimi $(\Delta \mathrm{E}) 24$ saat, 1 hafta ve 6 hafta sonra ölçüldü. Veriler ANOVA ve Kruskall Wallis testleri ile analiz edildi $(p=0.05)$.

Bulgular: Saklama ortamı ve zaman mikrohibrit kompozitin yüzey mikrosertliğini hiçbir grupta etkilemedi $(p>0.05)$. Modeling Liquid uygulanması örnekler kahvede saklandığında tüm saklama süreleri için örneklerin pürüzlüğünü olumlu yönde etkiledi $(p<0.05)$. Kontrol grubunda ve Modeling Liquid uygulanan grupta diğer gruplara göre örnekler kahvede saklandığında tüm saklama süreleri için daha az renk değişimi sergiledi $(p<0.05)$.

Sonuç: Mikrohibrit kompoziti şekillendirmek için kullanılan farklı tipteki modelasyon likitleri mikrohibrit kompozitin yüzey özelliklerini ve renk değişimini etkileyebilir.

\section{ANAHTAR KELIMELER}

Mikrohibrit kompozit, mikrosertlik, modelasyon rezini, renk değişimi, yüzey pürüzlülüğü

\section{ABSTRACT}

Effects of resins used for shaping composite restorations on the surface properties of a microhybrid composite

Background: To investigate the effect of different type of modeling agents on surface microhardness, roughness and color change of a micro-hybrid composite stored in coffee.

Methods: Total of 64 cylinder-shaped micro-hybrid composite (Essentia Universal, GC, Tokyo, Japan) specimens were prepared using a Teflon mold $(12 \mathrm{~mm}$ diameter $\times 2 \mathrm{~mm}$ thickness) according to the following groups; Group 1: Control (no modeling agent), Group 2: Modeling Liquid (GC), Group 3: G-Premio Bond (GC), Group 4: OptiBond XTR Primer (KavoKerr). The modeling agents was only applied to the micro-hybrid composite surface while placing, and a Mylar strip was used at top of the specimens, then polymerized for $20 \mathrm{sec}$. The specimens were polished with 2500-3000 grid SiC-papers and randomly divided into 2 groups $(n=8)$ according to the storage media: distilled water or coffee in an incubator at $37^{\circ} \mathrm{C}$. Surface microhardness $(\mathrm{VHN})$, roughness $(\mathrm{Ra})$, and color change $(\Delta \mathrm{E})$ was measured 24h, 1-week and 6-week after storage. Data was analyzed with ANOVA and Kruskall Wallis tests $(p=0.05)$

Results: Storage media and time didn't influence the VHN of the micro-hybrid composite in each group $(p>0.05)$. Modeling Liquid application was improved Ra values when the specimens stored in coffee at each storage time $(p<0.05)$. Control and Modeling Liquid application groups were exhibited lower $\Delta \mathrm{E}$ values than the other groups when stored in coffee at all storage time $(p<0.05)$.

Conclusion: Application of different types of modeling agents for shaping the micro-hybrid composite could affect the surface properties and color change.

\section{KEYWORDS}

Microhybrid composite, microhardness, modeling resins, color change, surface roughness

\footnotetext{
${ }^{*}$ Bu araştırma 5-7 Nisan 2019 tarihlerinde Hacettepe Üniversitesi Diş Hekimliği Fakültesi 1. Uluslararası Öğrenci Kongresinde poster sunumu olarak sunulmuştur.

${ }^{\alpha}$ Hacettepe Üniversitesi Diş Hekimliği Fakültesi Restoratif Diş Tedavisi Anabilim Dalı, Ankara
} 
Kompozitler günümüzde, diş hekimliğinde adeziv teknolojisinin gelişmesiyle en çok tercih edilen direkt restoratif materyallerdir. ${ }^{1}$ Minimal girişimsel uygulamalara imkan vermesi, doğal diş yapısına benzer optik özellikler sergileyebiliyor ve diş anatomisini oluşturulabiliyor olması kompozitlerin kullanılmasını arttırıcı özellikleri arasında yer almaktadır. $^{2} \quad$ Kompozit restorasyonların tabakalı olarak uygulanması, yerleştirilmesi ve form verilmesi sırasında sıklıkla yapılan bir yöntemdir. ${ }^{3}$ Ancak, kompozitler içerisindeki visköz rezin monomerler dişin doğal anatomik şeklini oluşturmayı zorlaştırabilir. Kompozitin adaptasyonunu ve şekillendirmesini kolaylaştırmak için bazı modelasyon ajanları ve ekipmanları önerilmektedir. ${ }^{4,5} \quad$ Üreticiler tarafından uygulanabilirliği açı olarak belirtilmemiş olmasına rağmen, kompozitlerin şekillendirilmesinde adezivler de kullanılmaktadır.

Kompozitlerin tabakalı olarak uygulanması sırasında kompozitin el aletine yapışması sıklıkla karşılaşılan bir sorundur. ${ }^{6}$ El aletlerinin veya fırçaların rezin monomer içerikli likitler ile ıslatılarak kullanılmasının kompozitin şekillendirmesini kolaylaştırdığını ve kompozitin el aletine yapışması sorununu ortadan kaldırdığını gösteren çalışmalar bulunmaktadır. ${ }^{6,7} \mathrm{Bu}$ nedenle, klinisyenler tabakalama tekniğini uygularken kompozitin el aletine yapışmasını en aza indirmek, manipülasyonunu kolaylaştırmak ve adaptasyonunu arttırmak için farklı likitler kullanmaktadırlar. ${ }^{8}$ Bu yöntemler sıklıkla tercih edilmesine rağmen, kompozit restorasyonların şekillendirilmesinde kullanılan farklı içeriklerdeki adezivlerin veya modelasyon rezinlerinin kompozitlerin yüzey mikrosertliğine, yüzey pürüzlülüğüne ve renk stabilitesine zaman içinde olan etkisi tam olarak bilinmemekle birlikte, etkilerini araştıran ve rapor eden literatürde az sayıda çalışma yer almaktadır. ${ }^{2,5,7}$

$\mathrm{Bu}$ in vitro çalışmada, kompozit uygulama aletleri ve fırça ile kullanılan farklı modelasyon rezinlerinin bir mikrohibrit kompozitin yüzey mikrosertliğine, yüzey pürüzlülüğüne ve renk değişimine olan etkisini incelemek amaçlandı. Çalışmada farklı modelasyon rezinlerinin mikrohibrit bir kompozitin distile suda veya kahvede 1 ve 6 hafta saklandıktan sonraki yüzey mikrosertliğine, yüzey pürüzlülüğüne ve renk değişimine etkisi olmayacağı hipotezi test edildi.

\section{GEREÇ VE YÖNTEM}

\section{Deneyin dizyanı ve örneklerin hazırlanması}

Çalışmada mikrohibrit kompozit olan Essentia Universal (GC Corp., Tokyo, Japonya) kullanılarak 64 adet kompozit örnek hazırlandı. Örneklerin hazırlanmasında $12 \mathrm{~mm}$ çapında $2 \mathrm{~mm}$ yüksekliğinde standart Teflon kalıplar kullanıldı. El aleti yardımıyla kalıplara yerleştirilen kompozitin en üst yüzeyine yapılan uygulamalara göre gruplar şu şekilde oluşturuldu: Grup 1: herhangi bir modelasyon rezininin uygulanmadığı grup (kontrol grubu); Grup 2: Modeling Liquid (GC Corp., Tokyo, Japonya) ile nemlendirilen samur fırça ile şekillendirilen grup; Grup 3: bir üniversal adeziv olan G-Premio Bond (GC Corp., Tokyo, Japonya) ile nemlendirilen mikro fırça kullanılarak şekillendirilen grup; Grup 4: iki aşamalı bir self adeziv sistemin birinci aşaması olan Optibond XTR Primer (Kerr Corp., Orange, CA, Amerika Birleşik Devletleri) ile nemlendirilen mikro fırça kullanılarak şekillendirilen grup. Çalışmada kullanılan materyallerin içerikleri ve üreticileri Tablo 1'de verilmektedir.

Tablo 1.

\section{Çalışmada kullanılan materyaller}

\begin{tabular}{|c|c|c|c|}
\hline Materyaller & İçerikleri & $\begin{array}{l}\text { Üretici } \\
\text { Firmaları }\end{array}$ & $\begin{array}{l}\text { Lot } \\
\text { Numaraları }\end{array}$ \\
\hline $\begin{array}{l}\text { Essentia Universal } \\
\text { (Mikrohibrit } \\
\text { kompozit) }\end{array}$ & $\begin{array}{l}\text { Matriks: UDMA, Bis-EMA, } \\
\text { Bis-GMA, TEGDMA Doldurucular: } \\
\text { Prepolimerize doldurucular, } \\
\text { baryum cam, silika } \\
\text { Hacimce doldurucu yüzdesi: } \% 65\end{array}$ & $\begin{array}{l}\text { GC } \\
\text { Corporation, } \\
\text { Tokyo, } \\
\text { Japonya }\end{array}$ & 178664 \\
\hline $\begin{array}{l}\text { Modeling Liquid } \\
\text { (Direkt kompozit } \\
\text { restorasyonları } \\
\text { şekillendirmek için } \\
\text { kullanılan likit) }\end{array}$ & $\begin{array}{l}\text { UDMA, 2-Hidroksi-1,3 } \\
\text { dimetakriloksipropan,2- } \\
\text { hidroksietil metakrilat }\end{array}$ & $\begin{array}{l}\text { GC } \\
\text { Corporation, } \\
\text { Tokyo, } \\
\text { Japonya }\end{array}$ & 1805171 \\
\hline $\begin{array}{l}\text { G-Premio Bond } \\
\text { (Üniversal adeziv) }\end{array}$ & $\begin{array}{l}\text { 10-metakriloloksideksil dihidrojen } \\
\text { fosfat, 4-metakriloloksietil } \\
\text { trimetilmetakrilat, } \\
\text { metakriloloksikakril trifosfat metil } \\
\text { metakrilat, metakrilat monomeri, } \\
\text { aseton, su, silika, başlatıcı }\end{array}$ & $\begin{array}{l}\text { GC } \\
\text { Corporation, } \\
\text { Tokyo, } \\
\text { Japonya }\end{array}$ & 1901092 \\
\hline $\begin{array}{l}\text { Optibond XTR } \\
\text { Primer } \\
\text { (Íki aşamalı self- } \\
\text { adeziv sisteme ait } \\
\text { primer) }\end{array}$ & $\begin{array}{l}\text { Gliserol fosfat dimetakrilat, } \\
\text { hidrofilik ko-monomerler, su, } \\
\text { etanol, aseton }\end{array}$ & $\begin{array}{l}\text { Kerr Corp., } \\
\text { Orange, CA, } \\
\text { Amerika } \\
\text { Birleşik } \\
\text { Devletleri }\end{array}$ & 6350939 \\
\hline
\end{tabular}

UDMA: Üretan dimetakrilat, , Bis-GMA: Bisfenol-A dimetakrilat, TEGDMA: Trietilen glikol dimetakrilat

Tüm örnekler, standart Teflon kalıplar düzgün yüzeyler oluşturulabilmesi için iki cam düzlem arasına yerleştirilerek ve kompozit yüzeylerine şeffaf bantlar temas edecek şekilde hazırlandı. Kompozit örnekler sadece üst yüzeylerinden 1200 $\mathrm{mW} / \mathrm{cm}^{2}$ ışık şiddetine sahip LED ışık cihazı (Woodpecker, Woodpecker Med. Instrument, Guilin, Çin) ile 20 saniye polimerize edildi. Cihazın Ișık şiddetinin kontrolü için bir radyometre (Model 100, Demetron/Kerr, Danbury, ABD) her 5 örnekte bir kullanıldı. Teflon kalıplardan çıkarılan polimerize edilmiş kompozit örneklerin alt yüzeylerine örnek numaraları kazındıktan sonra $37^{\circ} \mathrm{C}$ 'deki inkübatörde distile suda faklı bölmelere sahip polietilen kaplar içinde post-polimerizasyonun tamamlanması için 24 saat bekletildi. Bekleme süresinden sonra, örneklerin üst yüzeyleri 2500 ve 3000 gritlik silikon karbit 
kağıtlar ile su soğutması yapılarak polisaj makinasında (Mecapol P230, Presi, Grenoble, Fransa) polisaj yapıldı. Polisaj yapılan örneklerin üst yüzeylerinin mikrosertlik, pürüzlülük ve renk ölçümleri yapıldı ve baseline değerleri olarak kaydedildi. Örneklerin yarısı distile suda diğer yarısı kahve içeren kaplarda 1 ve 6 hafta süre saklandıktan sonra aynı parametrelerin ölçümleri tekrarlandı $(n=8)$.

Örnekleri renklendirmek için kullanılan kahve solüsyonu kaynatılan $500 \mathrm{~mL}$ distile suya $7,5 \mathrm{gr}$ granül kahve (Nescafé Classic; Nestlé) eklenmesiyle hazırlandı. Renklendirilmek için hazırlanan örnekler bu solüsyon içerisinde paslanmaz çelik kaplarda $37^{\circ} \mathrm{C}$ 'deki inkübatörde karanlık ortamda ölçümleri yapılanan kadar (1 ve 6 hafta) saklandı. ${ }^{9}$ Saklanan örneklerin bulunduğu kaplardaki renklendirme solüsyonu deney süresince her 2 günde bir taze olarak hazırlanarak yenilendi. Aynı şekilde distile suda bekletilen örneklerin distile suları da yenilendi. Ölçümler yapılmadan önce tüm örnekler su ile yıkadı ve hava ile kurutuldu.

\section{Örneklerin yüzey mikrosertlik ölçümü}

Kompozit örneklerin baseline, 1 ve 6 hafta sonra üst yüzeylerinin mikrosertlik değerlerinin belirlenmesi için bir mikrosertlik test cihazı (Shimadzu HMV/ 2000, Shimadzu Corporation, Kyoto, Japonya) kullanıldı ve ölçümler Vickers sertlik numarası (VHN) $\left(\mathrm{kg} / \mathrm{mm}^{2}\right)$ olarak kaydedildi. Yüzey sertliğinin belirlenmesi için gerekli olan çentik oluşturma işlemi 200 gramlık kuvvet 10 saniye uygulanarak sağlandı. Bir örneğin yüzeyinden $200 \mu \mathrm{m}$ aralıklarla 5 ölçüm yapıldı ve bu değerlerin ortalaması hesaplandı.

\section{Örneklerin yüzey pürüzlülüğünün ölçümü}

Kompozit örneklerin baseline, 1 ve 6 hafta sonra üst yüzeylerinin pürüzlülük değerleri bir profilometre cihazı (Perthometer M2, Mahr, Göttingen, Almanya) kullanılarak ölçüldü. Ölçümler $10 \mu \mathrm{m}$ çapında uç ile $0.25 \mathrm{~mm}$ eşik değerinde iz mesafesi $5.6 \mathrm{~mm}$ olacak şekilde yapıldı. Bir örneğin yüzeyinden örnek saat yönünde açıSı $45^{\circ}$ değiştirilerek beş farklı bölgesinden ölçüm elde edildi ve bu değerlerin ortalaması hesaplandı. Böylelikle, her örneğin yüzey pürüzlülük değeri $(R a)$ belirlendi.

\section{Örneklerin renk ölçümü}

Kompozit örneklerin baseline, 1 ve 6 hafta sonra renk dağılım değerleri $\left(L^{*}, a^{*}\right.$ ve $\left.b^{\star}\right)$ bir dijital spektrofotometre cihazı (VITA Easy Shade, Vident, Brea, CA, Amerika Birleşik Devletleri) kullanılarak ölçüldü. Ölçümler örneklerin orta bölgesinden yapıldı üç kez tekrarlandı, elde edilen değerlerin ortalaması kaydedildi. Dijital spektrofotometre cihazı her ölçümden önce üreticisinin talimatları doğrultusunda kalibre edildi. Her gruptaki örneklerin; baseline_1 hafta, baseline_6 hafta ve 1 hafta_6 hafta aralıklarındaki renk değişim değerleri $(\Delta \mathrm{E})$ aşağıdaki formül kullanılarak hesapladı.

$$
\Delta \mathrm{E}=\left[(\Delta \mathrm{L})^{2}+(\Delta \mathrm{a})^{2}+(\Delta \mathrm{b})^{2}\right]^{1 / 2}
$$

Tarama Elektron Mikroskobu görüntülerinin elde edilmesi

Taramalı elektron mikroskobu görüntülemelerinin elde edilmesi için Nova NanoSEM 430 (FEl, Oregon, Amerika Birleşik Devletleri) cihazı kullanıldı ve her gruba ait 3'er örnek hazırlandı. Hazırlanan örnekler 24 saat ve 6 hafta distile suda, 6 hafta renklendirme solüsyonu olan kahvede saklandıktan sonra x2000 büyütme ile görüntülendi. Görüntüleme öncesinde örneklerin incelenecek olan üst yüzeyleri $5 \mu \mathrm{m}$ boyutlarında altın ile kaplandı.

\section{İstatistiksel analiz}

Çalışmadan elde edilen verilerin analizinde SPSS 20.0 versiyonlu yazılım programı (IBM SPSS Statistics, Şikago, IL, Amerika Birleşik Devletleri) kullanıldı. Tekrarlayan ölçümler ANOVA ve Kruskall Wallis testleri ile 'modelasyon rezini', 'saklama ortami' ve 'saklama süresi' faktörlerinin test edilen grupların yüzey mikrosertliği (VHN), pürüzlülüğü $(R a)$ ve renk değişimi $(\Delta E)$ üzerine etkileri analiz edildi $(p=0.05)$.

\section{BULGULAR}

\section{Yüzey mikrosertlik bulguları}

Çalışmada elde edilen yüzey mikrosertlik bulguları Tablo 2'de gösterilmektedir. Bu bulgulara göre test edilen mikrohibrit kompozitin yüzey mikrosertlik değerlerinin kullanılan modelasyon rezininden, saklandığı ortamdan (distile su veya kahve), saklanma süresinden etkilenmedi görüldü. Elde edilen değerler arasında istatistiksel olarak herhangi bir farka rastlanmadı $(p>0.05)$. Tüm gruplar için örneklerin distile suda veya kahvede saklanması yüzey mikrosertlik değerlerine etkide bulunmadı $(p>0.05)$.

\section{Yüzey pürüzlülük bulguları}

Çalışmada elde edilen yüzey pürüzlülük bulguları Tablo 3'te gösterilmektedir. Test edilen mikrohibrit kompozitin yüzey pürüzlülüğü distile suda saklandığında farklı modelasyon rezinlerinden ve saklanma süresinden etkilenmedi ve bu faktörler istatistiksel olarak anlamlı farklı̆ı̆a neden olmadı $(p>0.05)$. Kahvede saklanan mikrohibrit kompozit örneklerin yüzey pürüzlülük değerleri arasında istatistiksel olarak anlamlı farklılık görüldü $(p<0.05)$. Modeling Liquid ile hazırlanan gruba ait örneklerin tüm ölçüm zamanlarında (baseline, 1 ve 6 hafta) diğer 
Tablo 2.

Test edilen grupların yüzey mikrosertlik değerleri (VHN) (Median ve \%25-75 değerleri)

\begin{tabular}{|lccccccccc|}
\multirow{2}{*}{ Gruplar } & \multicolumn{5}{c}{ Distile su } & \multicolumn{5}{c|}{ Kahve } \\
\cline { 2 - 9 } & Baseline & $\mathbf{1}$ hafta & $\mathbf{6}$ hafta & $\mathbf{p}$ & Baseline & $\mathbf{1}$ hafta & $\mathbf{6}$ hafta & $\mathbf{p}$ \\
\hline Kontrol & $45.06(42.12-$ & $45.21(38.93-$ & $44.93(42.36-$ & 0.228 & $44.87(40.35-$ & $43.66(39.34-$ & $42.43(39.56-$ & 0.285 \\
\hline Modeling & $45.88)$ & $45.18)$ & $46.45)$ & & $45.08)$ & $45.41)$ & $43.39)$ & \\
Liquid & $45.62(44.33-$ & $46.51(43.74-$ & $45.97(43.87-$ & 0.290 & $45.87(40.13-$ & $45.19(45.83-$ & $44.16(42.87-$ & 0.552 \\
\hline Üniversal & $45.41)$ & $48.67)$ & $49.73)$ & & $47.62)$ & $48.06)$ & $47.35)$ & \\
Adeziv & $44.29(43.74-$ & $43.87(45.03-$ & $43.48(43.68-$ & 0.786 & $44.53(43.14-$ & $44.93(44.55-$ & $43.32(43.93-$ & 0.540 \\
\hline Primer & $45.78)$ & $50.56)$ & $44.65)$ & & $50.87)$ & $49.70)$ & $51.19)$ & \\
\hline p & $45.52 .26-$ & $42.11(43.63-$ & $42.91(42.04-$ & 0.916 & $41.76(37.41-$ & $41.26(37.39-$ & $42.33(37.59-$ & 0.489 \\
\hline
\end{tabular}

* Her sütundaki gruplar arasındaki istatistiksel olarak anlamlı farklı göstermektedir $(p<0.05)$

Tablo 3.

Test edilen grupların yüzey pürüzlülük değerleri (Ra) (Median ve \%25-75 değerleri)

\begin{tabular}{|c|c|c|c|c|c|c|c|c|}
\hline \multirow{2}{*}{ Gruplar } & \multicolumn{4}{|c|}{ Distile su } & \multicolumn{4}{|c|}{ Kahve } \\
\hline & Baseline & 1 hafta & 6 hafta & $p$ & Baseline & 1 hafta & 6 hafta & $p$ \\
\hline Kontrol & $\begin{array}{c}0.21(0.15- \\
0.47)\end{array}$ & $\begin{array}{c}0.24(0.19- \\
0.38)\end{array}$ & $\begin{array}{c}0.25(0.15- \\
0.43)\end{array}$ & 0.986 & $\begin{array}{c}0.20(0.16- \\
0.24)\end{array}$ & $\begin{array}{c}0.24(0.16- \\
0.33)\end{array}$ & $\begin{array}{c}0.24(0.19- \\
0.30)\end{array}$ & 0.776 \\
\hline $\begin{array}{l}\text { Modeling } \\
\text { Liquid }\end{array}$ & $\begin{array}{c}0.13(0.12- \\
0.18)\end{array}$ & $\begin{array}{c}0.16(0.12- \\
0.24)\end{array}$ & $\begin{array}{c}0.17(0.13- \\
0.18)\end{array}$ & 0.887 & $\begin{array}{c}0.11(0.09- \\
0.20)^{*}\end{array}$ & $\begin{array}{c}0.14(0.13- \\
0.20)^{*}\end{array}$ & $\begin{array}{c}0.17(0.15- \\
0.24)^{*}\end{array}$ & 0.189 \\
\hline $\begin{array}{l}\text { Üniversal } \\
\text { Adeziv }\end{array}$ & $\begin{array}{c}0.14(0.13- \\
0.20)\end{array}$ & $\begin{array}{c}0.15(0.11- \\
0.30)\end{array}$ & $\begin{array}{c}0.20(0.13- \\
0.26)\end{array}$ & 0.647 & $\begin{array}{c}0.18(0.12- \\
0.24)\end{array}$ & $\begin{array}{c}0.19(0.16- \\
0.23)\end{array}$ & $\begin{array}{c}0.20(0.20- \\
0.26)\end{array}$ & 0.447 \\
\hline Primer & $\begin{array}{c}0.18(0.14- \\
0.39)^{* *}\end{array}$ & $\begin{array}{c}0.19(0.14- \\
0.39)^{\star *}\end{array}$ & $\begin{array}{c}0.25(0.16- \\
0.39)^{\star *}\end{array}$ & 0.426 & $\begin{array}{c}0.33(0.15- \\
0.45)^{\star *}\end{array}$ & $\begin{array}{c}0.36(0.14- \\
0.32)^{\star \star}\end{array}$ & $\begin{array}{c}0.38(0.19- \\
0.36)^{\star *}\end{array}$ & 0.526 \\
\hline$p$ & 0.153 & 0.183 & 0.130 & & 0.046 & 0.039 & 0.031 & \\
\hline
\end{tabular}

* Her sütundaki gruplar arasındaki istatistiksel olarak anlamlı farklı göstermektedir $(p<0.05)$

** Her satırdaki ölçüm zamanları arasındaki istatistiksel olarak anlamlı farklı göstermektedir $(p<0.05)$

\section{Tablo 4.}

Test edilen grupların belirtilen ölçüm zamanları arasındaki (Baseline_1 hafta, Baseline_6 hafta, 1 hafta_6 hafta) renk değişim ( $\Delta \mathrm{E})$ değerleri (Median ve \%25-75 değerleri)

\begin{tabular}{|c|c|c|c|c|c|c|c|c|}
\hline \multirow{2}{*}{ Gruplar } & \multicolumn{4}{|c|}{ Distile su } & \multicolumn{4}{|c|}{ Kahve } \\
\hline & $\begin{array}{c}\text { Baseline_1 } \\
\text { hafta }\end{array}$ & $\begin{array}{c}\text { Baseline_6 } \\
\text { hafta }\end{array}$ & $\begin{array}{c}1 \text { hafta_ } 6 \\
\text { hafta }\end{array}$ & $\mathbf{p}$ & $\begin{array}{c}\text { Baseline_1 } \\
\text { hafta }\end{array}$ & $\begin{array}{c}\text { Baseline_6 } \\
\text { hafta }\end{array}$ & $\begin{array}{c}1 \text { hafta_6 } \\
\text { hafta }\end{array}$ & $p$ \\
\hline Kontrol & $\begin{array}{c}1.72(0.91- \\
3.04)\end{array}$ & $\begin{array}{c}2.24(1.59- \\
3.81)\end{array}$ & $\begin{array}{c}2.28(1.76- \\
3.13)\end{array}$ & 0.417 & $\begin{array}{c}1.95(1.60- \\
2.45)\end{array}$ & $\begin{array}{c}2.33(1.91- \\
3.27)\end{array}$ & $\begin{array}{c}2.24(1.86- \\
3.11)\end{array}$ & 0.417 \\
\hline $\begin{array}{l}\text { Modeling } \\
\text { Liquid }\end{array}$ & $\begin{array}{c}1.75(0.64- \\
2.93)\end{array}$ & $\begin{array}{c}2.22(2.61- \\
4.49)\end{array}$ & $\begin{array}{c}2.32(1.89- \\
3.06)\end{array}$ & 0.072 & $\begin{array}{c}1.83(1.58- \\
2.39)\end{array}$ & $\begin{array}{c}2.37(2.02- \\
3.51)\end{array}$ & $\begin{array}{c}2.25(1.71- \\
3.08)\end{array}$ & 0.325 \\
\hline $\begin{array}{l}\text { Üniversal } \\
\text { Adeziv }\end{array}$ & $\begin{array}{c}2.90(2.71- \\
3.70)^{\star \star}\end{array}$ & $\begin{array}{c}2.96(2.76- \\
3.76)^{\star \star}\end{array}$ & $\begin{array}{c}2.70(1.90- \\
2.91)^{\star \star}\end{array}$ & 0.607 & $\begin{array}{c}3.53(2.47- \\
3.99)^{\star \star}\end{array}$ & $\begin{array}{c}4.83(3.49 \\
4.99)^{\star \star}\end{array}$ & $\begin{array}{c}4.30(3.30- \\
5.27)^{\star \star}\end{array}$ & 0.197 \\
\hline Primer & $\begin{array}{c}2.16(1.44- \\
3.68)^{\star *}\end{array}$ & $\begin{array}{c}2.35(1.95- \\
4.41)^{\star *}\end{array}$ & $\begin{array}{c}2.48(1.63- \\
3.54)^{\star *}\end{array}$ & 0.687 & $\begin{array}{c}3.29(1.52- \\
5.45)^{\star \star}\end{array}$ & $\begin{array}{c}5.64(3.53- \\
9.74)^{* *}\end{array}$ & $\begin{array}{c}4.12(3.31- \\
6.58)^{\star *}\end{array}$ & 0.135 \\
\hline$p$ & 0.226 & 0.285 & 0.842 & & 0.042 & 0.025 & 0.026 & \\
\hline
\end{tabular}

* Her sütundaki gruplar arasındaki istatistiksel olarak anlamlı farklı göstermektedir $(p<0.05)$.

** Her satırdaki ölçüm zamanları arasındaki istatistiksel olarak anlamlı farklı göstermektedir $(p<0.05)$ 
gruplara göre anlamlı olarak daha düşük pürüzlülük değerleri gösterdiği belirlendi. Bunun yanı sıra kahvede saklanan örneklerin yüzey pürüzlülük değerlerinin saklama süresinden etkilenmediği izlendi ( $p>0.05)$. Tüm ölçüm zamanları için 2 aşamalı self adeziv sistemin primer'ı ile hazırlanan örneklerin yüzey pürüzlülük değerleri kahvede bekletildiğinde suda bekletilenlere göre istatistiksel olarak anlamlı olarak daha yüksek olduğu görüldü $(p<0.05)$. Bu örneklerin kahvede saklanması yüzey pürüzlülük değerlerini olumsuz etkiledi.

\section{Renk değisşimi bulguları}

Çalışmada baseline_1 hafta, baseline_6 hafta ve 1 hafta_6 hafta aralıklarında elde edilen renk değişim $(\Delta \mathrm{E})$ bulguları Tablo 4'te gösterilmektedir. Gruplarda belirlenen renk değişim değerleri $1.72-5.64 \Delta \mathrm{E}$ birim aralığında ölçüldü. Distile suda bekletilen örneklerde gruplar arasında ve farklı zaman aralıklarında yapılan renk değişim değerleri arasında istatistiksel olarak anlamlı bir fark oluşmadığı görüldü ve test edilen mikrohibrit kompozit distile suda saklandığında farklı modelasyon rezinlerinin ve saklanma süresinin renk değişimine neden olmadığı belirlendi $(p>0.05)$. Kahvede saklanan mikrohibrit kompozitin renk değişim değerleri gruplar arasında istatistiksel olarak anlamlı farklılıklar gösterdi $(p<0.05)$. Tüm renk değişim ölçüm aralıklarında kontrol grubu örneklerinde ve Modeling Liquid kullanılarak hazırlanan örneklerde diğer gruplara göre anlamlı olarak daha az renk değişim olduğu belirlendi. Bununla birlikte, grupların hiçbirinde kahvede saklanan örneklerin baseline_1 hafta, baseline_6 hafta ve 1 hafta_6 hafta aralıklarında yapılan renk değişim değerleri arasında anlamlı fark oluşmadı $(p>0.05)$. Tüm ölçüm zamanları için üniversal adeziv ve 2 aşamalı self adeziv sistemin primer'ı ile hazırlanan örneklerin renk değişim değerleri kahvede bekletildiğinde suda bekletilenlere göre istatistiksel olarak anlamlı olarak daha yüksek olduğu görüldü $(p<0.05)$. Bu örneklerin kahvede saklanması renk değişim değerlerini olumsuz etkiledi. Kontrol ve Modeling Liquid uygulanan gruplarında ise kahve renk değişin değerlerine etkide bulunmadı.

\section{Tarama Elektron Mikroskobu görüntülerinin bulguları}

(SEM)

Resim 1'de tüm gruplara ait 24 saat ve 6 hafta distile suda, 6 hafta kahvede saklanan örneklerin x2000 büyütme ile alınan SEM görüntüleri gösterilmektedir. Farklı saklama ortamlarında 6 hafta tutulan örnekler ile kontrol grubu olarak belirlenen örneğin SEM görüntüleri incelendiğinde örnek yüzeylerinde net bir bozulma olmadığı görüldü.

\section{TARTIŞMA}

Bazı klinisyenler tarafından kompozit restorasyonların şekillendirilmesinde kullanılan modelasyon rezinlerinin uygulamayı kolaylaştırdığı ifade edilmektedir. Modelasyon rezini ile nemlendirilen samur fırçanın kompozite daha az yapışması suretiyle kompozitin ağız içinde kolay ve hızlı uygulanmasına ve şekillendirilmesine olanak sağlamaktadır. Nemlendirilmiş fırçanın son kompozit tabakasının uygulanmasında kullanılması yüzeyi etkili bir şekilde pürüzsüzleştirirken çok daha düzgün bir yüzey elde edilmesine imkân vermektedir. $\mathrm{Bu}$ işlem, restorasyonun bitirme prosedürünü kolaylaştırır ve hekime önemli bir zaman kazancı sağlamaktadır. Bununla birlikte, bu rezinlerin, bileşiklerinden dolayı kompozit restorasyonların özellikle restorasyonun yüzey mikrosertliğinde, pürüzlülüğünde ve renk stabilitesinde zamanla meydana gelebilecek değişiklikler konusunda şüpheler ortaya çıkmıştır. ${ }^{4,10} \mathrm{Bu}$ nedenle, bu in vitro çalışmada, kompozit uygulama aletleri ve fırça ile kullanılan farklı modelasyon rezinlerinin bir mikrohibrit kompozitin yüzey mikrosertliğine, yüzey pürüzlülüğüne ve renk değişimine olan etkisi incelendi.

Çalışmada farklı modelasyon rezinlerinin mikrohibrit bir kompozitin distile suda veya kahvede 1 ve 6 hafta saklandıktan sonra yüzey mikrosertliğine etkisinin olmadığı, ancak yüzey pürüzlülüğüne ve renk değişimine etkisi olduğu görüldü ve test edilen hipotez kısmen reddedildi.

Rezin adezivler gibi düşük viskoziteli materyallerin kompozitlerin şekillendirilmesinde modelasyon rezini olarak kullanımasının özellikle kompozit tabaklarının şekillendirilmesinde ve yeterli adaptasyonunda başarılı klinik sonuçlar elde etmede bir yöntem olduğu rapor edilmiş olmasına rağmen bu şekilde kullanılmasını destekleyen bilimsel kanıtlar yeterli değildir.

Estetik restorasyonların şekillendirilmesi ve adaptasyonu sırasında modelasyon rezini olarak çoğunlukla adezivlerin kullanılıyor olması göz önüne alındığında, bu tekniğin mikrohibrit kompozitin yüzey özelliklerinin ve renk stabilitesinin olumsuz etkilenip etkilenmediğini doğrulamak bu çalışmayı ilginç hale getirmektedir. Munchow ve ark'nın ${ }^{11}$ çalışması gibi bizim çalışmamızda, test edilen modelasyon rezininin mikrohibrit kompoziti şekillendirmek ve adaptasyonu için kullanılmasının olumlu etkilerini gösteren öncü çalışmalardan biridir.

Çalışmadan elde edilen yüzey mikrosertlik değerlerine ait bulgular incelendiğinde test edilen mikrohibrit kompozitin yüzey mikrosertlik değerlerinin modelasyon rezinlerinden, saklanma ortamından veya saklanma zamanından herhangi bir şekilde etkilenmediği görüldü (Tablo 2). Ye ve ark.'nı ${ }^{12}$ yaptığı çalışma ile benzer olarak çalışmamızda mikrohibrit kompozit yüzeyini şekillendirmek ve adaptasyonu arttırmak amacıyla 

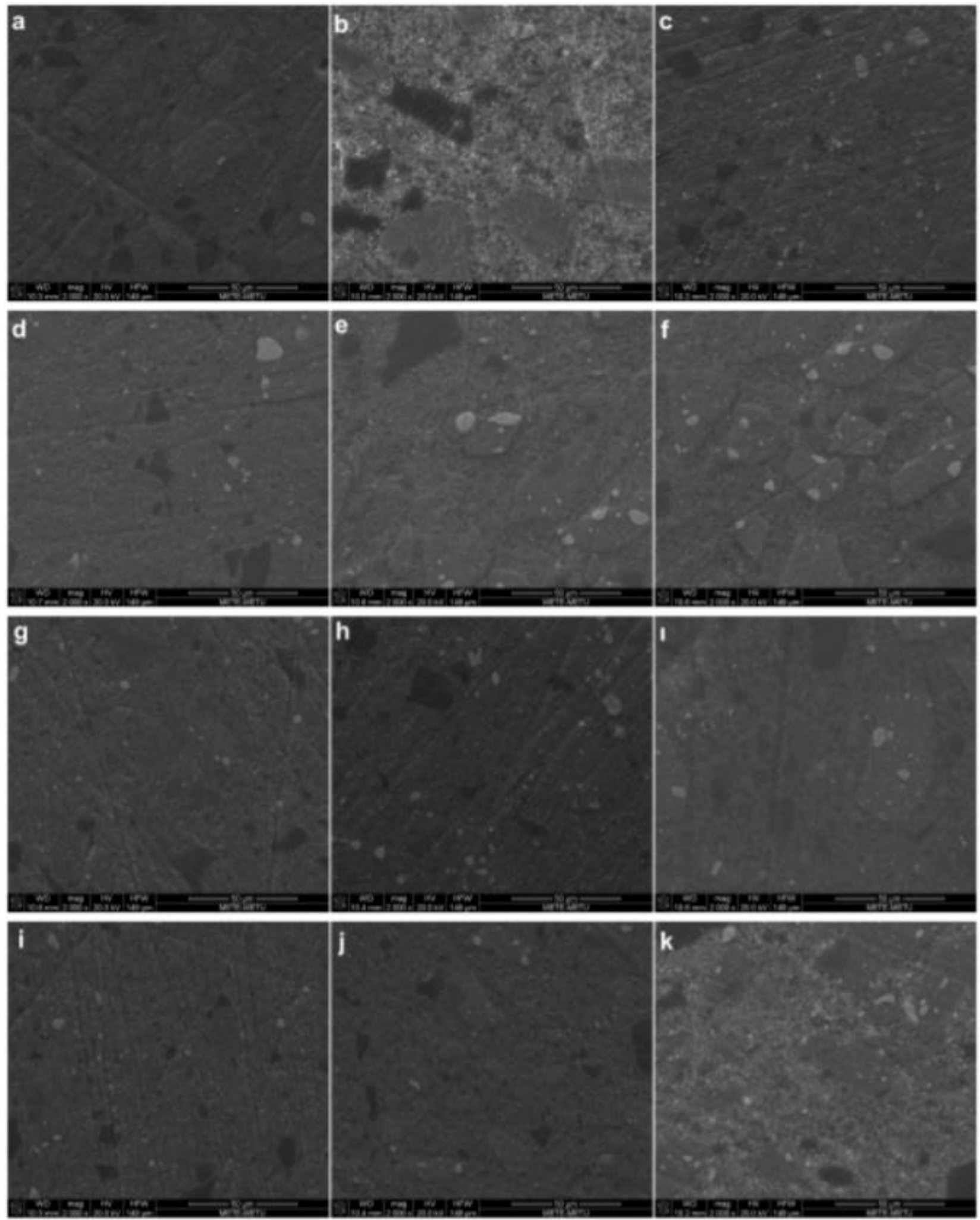

Resim 1.

Mikrohibrit kompozit örneklerinin yüzey özelliklerini gösteren x2000 büyütmedeki SEM görüntüleri.

Kontrol grubu: (a) 24 saat distile suda bekletilen örneğin görüntüsü, (b) 6 hafta distile suda bekletilen örneğin görüntüsü, (c) 6 hafta kahvede bekletilen örneğin görüntüsü. Modeling Liquid'ın kullanıldığı grup: (d) 24 saat distile suda bekletilen örneğin görüntüsü, (e) 6 hafta distile suda bekletilen örneğin görüntüsü, (f) 6 hafta kahvede bekletilen örneğin görüntüsü. Üniversal adezivin kullanıldığı grup: (g) 24 saat distile suda bekletilen örneğin görüntüsü, (h) 6 hafta distile suda bekletilen örneğin görüntüsü, (1) 6 hafta kahvede bekletilen örneğin görüntüsü. İki aşamalı self adeziv sistemin primer'ının kullanıldığı grup: (i) 24 saat distile suda bekletilen örneğin görüntüsü, (j) 6 hafta distile suda bekletilen örneğin görüntüsü, (k) 6 hafta kahvede bekletilen örneğin görüntüsü. 
uygulanan üniversal adezivin, kompozitlerin şekillendirilmesinde kullanılmak üzere üretilen modelasyon likidinin ve 2 aşamalı self-adeziv sistemin ilk aşaması olan primer'ın kompozitin üst yüzeyinde kusurların/boşlukların oluşmasını önlediği ve yüzey özelliklerini olumsuz etkilemediği belirlendi.

Çalışmamızda kullandığımız mikrohibrit yapıdaki kompozitin (Essentia Universal) yüzey mikrosertliği bulguları Tuncer ve ark.'nın modelasyon rezini ile hazırladıkları $(39 \pm 2)$ ve polyester şeffaf bant altında polimerize ettikleri mikrohibrit doldurucu içeriğine sahip kompozitin (Gradia Direct Posterior) modelasyon rezini kullanmadan hazırladıkları kontrol grubuna $(43 \pm 3)$ göre anlamlı derecede düşük buldukları mikrosertlik değerleri ile çelişmektedir. ${ }^{10}$ Araştırmacılar, bulgularını kullandıkları modelasyon rezininin test edilen kompozitlerin yüzeylerinde rezin içeriği bakımından zengin bir tabaka oluşturmasıyla ilişkilendirmişlerdir.

Bazı rezin içerikli likitler kompozitler için daha pürüzsüz yüzeyler oluşturmak amacıyla önerilmiştir. ${ }^{13,14}$ Bununla birlikte, rezin içerikli likitler ile kompozitlerde düzenli bir yüzey elde etmenin zor olduğu da gösterilmiştir. ${ }^{9}$

$\mathrm{Bu}$ çalışmanın yüzey pürüzlülük değerleri incelendiğinde Modeling Liquid ve üniversal adeziv ile hazırlanan grupların yüzey pürüzlülük değerlerinin tüm saklama koşullarında plak birikimi için eşik pürüzlülük değeri olan 0.20'nin altında olduğu görüldü ${ }^{15}$ ve Modeling Liquid ile hazırlanan gruba ait örnekler kahvede saklandığında diğer gruplara göre tüm ölçüm zamanlarında daha düşük pürüzlülük değerleri sergiledi. $\mathrm{Bu}$ durum kullanılan modelasyon likidinin test edilen kompozitin rezin içeriğine benzer bir yapıya sahip olmasıyla açıklanabilirken, en yüksek pürüzlülük değerlerinin 2 aşamalı self-adeziv sistemin primer'ı kullanıldığında oluşması bu materyalin içeriğinde çözücü olarak etanol ve asetonun yer alıyor olmasıyla ilişkilendirilebilir, daha önceki çalışmalarda da gösterildiği üzere bu çözücüler kompozitlerin yüzeylerinde bozulmalara, mikro boyutlarda çatlakların oluşmasına ve rezin matriks yapısının uzaklaşmasına neden olduğu bildirilmiştir. 4,5,6,11

$\mathrm{Bu}$ bulgular, test edilen Modeling Liquid materyalinin mikrohibrit kompozitin yüzey özelliklerini iyileştirdiği ve restorasyonun üst yüzeyinde düzensizlik ve defekt oluşumunu önlediğini doğrulamaktadır ve kompozitin uygulanması sırasında kompozitin el aletine yapışmasını ortadan kaldırmasıyla açıklanabilir.

Aynı zamanda, bu çalışmanın sonuçları, saklama ortamının (kahve), belirtilen saklama zamanlarında mikrohibrit kompozitin yüzey pürüzlülüğünü etkilemediğini göstermektedir. Çalışmanın sınırlarından biri, saklama zamanının 6 hafta ile sınırlı tutulmasıdır, uzun dönemli yaşlandırma veya termal siklus işlemlerinin uygulanması çalışma sonuçlarını etkileyebilecek faktörlerdir. ${ }^{16,17}$
En az renk değişim $(\Delta \mathrm{E})$ değeri özellikle estetik kaygılara neden olabilecek kompozit restorasyonlardan beklenen en önemli özelliklerden biridir. Bununla birlikte, kompozitler polimerik yapılarından dolayı bozulmaya meyilli materyallerdir ve bu bozulma zamanla renklerinde değişiklikler görülmesine neden olabilir. Son zamanlarda yayınlanan çalışmalara göre adeziv rezinler gibi modelasyon rezinlerinin kompozit tabakaları arasında adaptasyonu arttırmada ve kompozitlerin renklenmesini önlemede başarılı olabilmektedir. ${ }^{5,11}$

Bu çalışmanın amaçlarından biri, modelasyon rezinleri ile hazırlanan mikrohibrit kompozitin renginin, distile su veya kahvede 6 hafta saklandıktan sonra değişiklik gösterip göstermeyeceğini araştırmaktır. Yapılan analizlerin sonucunda test edilen mikrohibrit kompozitin renk değişimi kullanılan modelasyon rezinin tipine bağlı olarak farklılık gösterdi. Distile su, örneklerde saklama zamanlarından bağımsız olarak herhangi bir renk değişimine neden olmazken aynı durum kahve için geçerlilik göstermedi. Kontrol grubu ve Modeling Liquid uygulanarak hazırlanan örnek grubu kahvede saklandığında tüm ölçüm zaman aralıklarında renk değişimi oluşturmadı. Bu bulgular, kullanılan modelasyon rezininin tipinin, kompozitin renk stabilitesi üzerinde önemli bir rol oynadığını göstermektedir.

Üniversal adeziv ve 2 aşamalı self adeziv sistemin primer'ı ile hazırlanan örneklerin kahvede saklanmasının yüksek renk değişim değerleri göstermesi; bu, polimer esaslı materyallerin hidrolize girme eğiliminin yüksek olması ile açıklanabilir. ${ }^{18}$ Ancak, su gibi kompozitler arasındaki moleküler bağları parçalayabilen çözücü bu çalışmada etkisini göstermezken, ${ }^{19}$ kahve bu etkiyi daha fazla oluşturarak renk değişimine neden oldu. Hidrofobik yapıda olan ve doldurucu içermeyen Modeling Liquid materyali çalışmada hidrolize karşı direnç göstererek mikrohibrit kompozitin renk stabilitesini koruyabildi. Bu bulgular, diğer çalışmalar ile de desteklenmektedir. ${ }^{4,11}$

Kompozit restorasyonların ideal olarak optik özelliklerinin zamanla değişmemelidir. Tuncer ve ark. yaptıkları çalışmada, test ettikleri metakrilat içerikli mikrohibrit kompozitlerden birinde (Gradia Direct Posterior) kontrol grubu ile modelasyon rezini kullanılarak hazırlanan gruplar arasında termal siklus sonrası renk değişimi olmadığını bildirilirken, diğerinde (Aelite All Purpose Body) termal siklus sonrası modelasyon rezini kullanılarak hazırlanan grupta kontrol grubuna göre anlamlı bir renk değişimi olduğu ve $\Delta \mathrm{E}$ değerinin arttığı bildirilmiştir. ${ }^{10}$ Kompozitlerin optik özelliklerinin, özellikle kompozitler ağız ortamına yerleştirildikten sonra maruz kalabileceği bozulma göz önüne alındığında, zaman içinde bu özelliklerin stabil kalması beklenmemektedir. ${ }^{20}$ Renk, kompozit restorasyonlar için modifikasyona oldukça duyarlı bir 
parametredir ve modelasyon rezinleri kullanılarak hazırlanan restorasyonlara özellikle dikkat edilmelidir, çünkü bu ajanlar yapay yaşlandırma işlemleri sonrasında kompozit restorasyonların rengini etkileyebilmektedir. ${ }^{4}$

Modeling Liquid kullanılarak hazırlanan örneklerin diğer modelasyon rezinleri ile hazırlanan gruplara göre daha iyi yüzey ve renk stabilitesi özellikleri göstermesine rağmen, SEM görüntülerinin analizinde (Resim 1), distile su veya kahvede saklanma süresinden sonra diğer gruplara göre daha düzgün ve pürüzsüz yüzeyler sergilediği gözlenmedi.

Tüm bu bulgular bir araya getirildiğinde çalışmanın hipotezi kısmen reddedildi. Kullanılan modelasyon rezininin tipi, saklanma ortamı ve saklanma süresi test edilen mikrohibrit kompozitin yüzey mikrosertliğini etkilemedi. Modeling Liquid diğer modelasyon rezinlerine göre örnekler kahvede saklandığında örneklerin yüzey pürüzlülüğünü ve renk değişimini daha az etkilediği belirlendi.

\section{SONUÇ}

$\mathrm{Bu}$ in vitro çalışmadan elde edilen bulgular ile aşağıdaki sonuçlar çıkarılabilir:

1. Modelasyon rezinlerinin kullanılması mikrohibrit kompozitin yüzey mikrosertliğini etkilemeyebilir.

2. Modeling Liquid kullanılması, diğer alternatif modelasyon rezinlerine kıyasla daha pürüzsüz bir yüzey sağlayabilir.

3. Test edilen mikrohibrit kompozitin renk stabilitesi, üst yüzeyini şekillendirmek için Modeling Liquid kullanarak korunabilir. 


\section{KAYNAKLAR}

1. Rosa WL, Piva E, Silva AF. Bond strength of universal adhesives: A systematic review and meta-analysis. J Dent 2015; 43: 765-76.

2. Nahsan FP, Mondelli RF, Franco EB, Naufel FS, Ueda JK, Schmitt VL, et al. Clinical strategies for esthetic excellence in anterior tooth restorations: understanding color and composite resin selection. $\mathrm{J}$ Appl Oral Sci 2012; 20: 151-6.

3. Pontons-Melo JC, Furuse AY, Mondelli J. A direct composite resin stratification technique for restoration of the smile. Quintessence Int 2011; 42: 205-11.

4. Sedrez-Porto JA, Munchow EA, Brondani LP, Cenci MS, Pereira-Cenci T. Effects of modeling liquid/resin and polishing on the color change of resin composite. Braz Oral Res 2016; 30: e88.

5. Sedrez-Porto JA, Munchow EA, Cenci MS, PereiraCenci T. Translucency and color stability of resin composite and dental adhesives as modeling liquids - A one-year evaluation. Braz Oral Res 2017; 31: e54.

6. Dunn WJ, Strong TC. Effect of alcohol and unfilled resin in the incremental buildup of resin composite. Quintessence Int 2007; 38: e20-6.

7. Barcellos DC, Pucci CR, Torres CR, Goto EH, Inocencio AC. Effects of resinous monomers used in restorative dental modeling on the cohesive strength of composite resin. J Adhes Dent 2008; 10: 351-4.

8. Perdigao J, Gomes G. Effect of instrument lubricant on the cohesive strength of a hybrid resin composite. Quintessence Int 2006; 37: 621-5.

9. Bertrand MF, Leforestier E, Muller M, Lupi-Pegurier L, Bolla M. Effect of surface penetrating sealant on surface texture and microhardness of composite resins. J Biomed Mater Res 2000; 53: 658663.

10. Tuncer S, Demirci M, Tiryaki M, Unlu N, Uysal O. The effect of a modeling resin and thermocycling on the surface hardness, roughness, and color of different resin composites. J Esthet Restor Dent 2013; 25: 40419.

11. Munchow EA, Sedrez-Porto JA, Piva E, Pereira-Cenci $\mathrm{T}$, Cenci MS. Use of dental adhesives as modeler liquid of resin composites. Dent Mater 2016; 32: 5707.

12. Ye Q, Spencer P, Wang Y, Misra A. Relationship of solvent to the photopolymerization process, properties, and structure in model dentin adhesives. $J$ Biomed Mater Res A 2007; 80: 342-50.

13.Perez Cdos R, Hirata RJ, da Silva AH, Sampaio EM, de Miranda MS. Effect of a glaze/composite sealant on the 3-D surface roughness of esthetic restorative materials. Oper Dent 2009; 34: 674-80.

14. Lowe RA. Using BisCover surface sealant/polish on direct and indirect composite and bisacrylic provisional restorations. Compend Contin Educ Dent 2004; 25: 400-1.
15.Bollen CM, Papaioanno W, Van Eldere J, Schepers E, Quirynen M, van Steenberghe D. The influence of abutment surface roughness on plaque accumulation and peri-implant mucositis. Clin Oral Implants Res 1996; 7: 201-11.

16. Roselino Lde M, Cruvinel DR, Chinelatti MA, Pires-de-Souza Fde C. Effect of brushing and accelerated ageing on color stability and surface roughness of composites. J Dent 2013; 41 Suppl 5: e54-61.

17. Catelan A, Briso AL, Sundfeld RH, Dos Santos $\mathrm{PH}$. Effect of artificial aging on the roughness and microhardness of sealed composites. J Esthet Restor Dent 2010; 22: 324-30.

18. Ferracane JL. Resin composite--state of the art. Dent Mater 2011; 27: 29-38.

19.Ghinea R, Perez MM, Herrera LJ, Rivas MJ, Yebra A, Paravina RD. Color difference thresholds in dental ceramics. J Dent 2010; 38 Suppl 2: e5764.

20.Prodan DA, Gasparik C, Mada DC, Miclaus V, Baciut M, Dudea D. Influence of opacity on the color stability of a nanocomposite. Clin Oral Investig 2015; 19: 867-75.

Yazışma Adresi:

Zeynep Bilge KÜTÜK

Hacettepe Üniversitesi

Diş Hekimliği Fakültesi

Restoratif Diş Tedavisi AD

06100, Sıhhiye, Ankara, Türkiye

Tel : : +90 5334202586

Faks : +903123104440

e-Posta: zeynepbilge.kutuk@hacettepe.edu.tr 